\title{
Clinical Laboratory Improvement Act
}

National Cancer Institute

\section{Source}

National Cancer Institute. Clinical Laboratory Improvement Act. NCI Thesaurus. Code C83475.

A Federal law establishing quality standards for all laboratory testing to ensure the accuracy, reliability and timeliness of patient test results regardless of where the test was performed and also to determine if laboratories are achieving those standards. 